\title{
Citation Practices in the Literature Review: A Contrastive Study of Sudanese and British Applied Linguistics Ph.D. Theses
}

\author{
Nauman Al Amin Ali ${ }^{1, *}$ \\ ${ }^{1}$ University of Khartoum, Sudan, on secondment to College of Science \& Arts, Al Baha University, Kingdom of \\ Saudi Arabia. \\ *Correspondence: College of Science \& Arts, Almikhwa, P. O. Box 1988, Saudi Arabia. Tel: 966-53-776-4570. \\ E-mail: alnauman888@gmail.com
}

Received: December 5, 2016

Accepted: December 16, 2016 Online Published: December 27, 2016

doi:10.5430/wjel.v6n4p25

URL: http://dx.doi.org/10.5430/wjel.v6n4p25

\begin{abstract}
Manifest intertextuality is a fundamental aspect of all academic discourse, and, hence, this study purports to explore the myriad functions of citation in a representative and contrastive corpus drawn from 20 Literature Review chapters in the domain of Applied Linguistics, and equally divided among Ph.D. theses successfully defended in Sudan and Britain. A variety of typologies were utilized to elicit citations, including Thompson's (2005) classification of integral and non-integral citations, together with Hyland's (2002) designation of denotative and evaluative functions associated with reporting verbs. Groom's (2000) and Petric's (2007) notions of averral and attribution, propositional responsibility and knowledge transformation also inform this investigation. Results indicate that the dense deployment of citations and the predilection both corpora have for integral structures, verbatim quotations and present active Discourse reporting verbs are largely dictated by the discursive and human-imbued nature of Applied Linguistics. On the other hand, the findings reveal that Sudanese candidates formally and functionally employ citations in manners markedly different from their British peers. Thus, the Sudanese corpus is characterized by blatant errors, repetition and awkwardness in both documenting sources and reporting the findings of research. Moreover, naïve unwarranted quotations and authorial evaluations were ubiquitously observed, as compared to the British corpus. More significantly, there were ample variations in the way in which the two groups conceive of the role of the Literature Review. While the British adopted a range of Writer-oriented and metadiscoursal strategies to amalgamate and integrate the cited materials within their mainstream arguments, the Sudanese candidates were strictly concerned with unmediated and uncontested attribution of ideas to their authors. Such is the synthetic nature of the resultant type of this Literature Review that the writer's textual voice is submerged under the sheer burden of successive descriptive citations, thus eclipsing almost all of the objectives of this chapter in critiquing sources and subordinating the cited literature to the overarching transformative perspective of the thesis writer. The Discussion is illuminated through extensive quotations from the two corpora.
\end{abstract}

Keywords: citation practices; Ph.D. theses; reporting verbs; attribution; genre analysis

\section{Introduction}

The Ph.D. degree is the culmination of academic achievement in Higher Education and may be regarded as the standard and core degree of academic practice (Pyhältö et al, 2012) and, indeed, a rite de passage for any prospective scholar. As a public demonstration, this unique genre fulfills the communicative purpose of attaining a $\mathrm{Ph}$. D. award by constituting a proof to the examiners of the eligibility of the candidate. Yet, the goals of Ph. D. education transcend granting a mere license. They also involve, according to Thompson (2001: 51), displaying knowledge and critical faculties in order to prove mastery and so gain admission to the discourse community. Equally, produced research should develop the student's research skills as to become an independent researcher in his own right(Brydon and Fleming, 2011: 996). In fact, it is distinguished research that is the defining feature of this genre, compared to threshold efforts such as the Master degree. Thesis writers have to convince the examiners not only of their digestion of the literature but also their occupation of a niche (Swales, 1990) or an uncharted knowledge territory and, thereby, extending the gamut of the discipline. Paradoxically enough, then, there is a tension at the 
heart of this advanced academic effort between the writer as a humble servant of the discipline (Hyland, 2001), evincing familiarity with the canonical texts of the discourse community, and the expectation that he builds on these very scaffoldings of prior research to prove the validity of his originality crucial for his scholarly initiation into the local and global community. In undertaking both of these endeavors, the candidate constantly has to have recourse to exemplary and accredited sources through manifest intertextuality (Fairclough, 1992: 217). The concept hearkens to Bakhtin's $(1981,1986)$ original anti- Coleridgean proposition that a literary text is a mosaic of prior styles, codes and plot structures. In EAP literature, intertextuality is interpreted as citation which is, according to Thomas and Hawes (1997), the attribution of propositional content to a source outside the author of the reporting article and marked by the presence of some signal of attribution. Citation is such a central aspect of all written research that Swales and Feak (2012) deem it to be the (original emphasis) defining feature of academic prose. It is instrumental to the integration of sources into the writers' argument and presenting persuasive conclusions. While citation permeates both professional genres such as the research articles and apprenticeship research such as the Master and Ph.D. genre, canonical studies (notably Hyland, 2000, 2002) have tended to privilege high-stake research genres regarded as a model for student writing. Yet, as Petric (2007: 239) notes, scholars and students write for different audiences, have different writing goals and employ different genres, all of which factors can impinge on their citation practices. Taking this cue, this study will investigate citations in the Ph.D. thesis, where textual attribution is almost invariably most concentrated in the Literature Review Chapter which constitutes an obligatory and integral preliminary part of the thesis. This study compares the deployment of intertextual ties in the Theoretical Framework Chapter in two corpora in Applied Linguistics Ph. D. theses drawn from Sudanese and British universities.

\section{Literature Review}

The Literature Review Chapter furnishes the conceptual framework in which the research is anchored and against which larger narrative the text is to be interpreted. It illustrates how a delineation of the gaps in previous literature can be analyzed to establish new vistas and methodologies and, again, how new claims relate to the tradition of the discipline. Citation of prior texts is, then, crucial to achieving these academic objectives. In fact, in many ways, citation functions mirror the role of the Literature Review itself. As a metadisoursal strategy, by acknowledging a debt to a precedent, a researcher not only displays allegiance to the discourse community and its norms to safeguard against unsubstantiated claims and establish his status as a credible and expert member. It also a persuasive means to seek the consensus of the discourse community which grants legitimacy to the new proposals seen as much rhetorically as objectively constructed (Bruffe, 1986; Kostoff, 1998; Hyland, 2002, 2205; White, 2004). Equally, writers must consolidate their arguments and provide a demonstration of the substantiality of their position in relation to the disciplinary heritage (Berkenkotter and Huckin, 1995: 11). Citations are employed to uncover shortcomings and controversies in the literature which are resolved in the research and, hence, illustrating, according to Charles (2006), how, while the research is novel, it arises out of current disciplinary knowledge, and, thus, constitutes a manifestation of an ongoing conversation of the discipline.

Following Swales' (1990) appropriation of information sciences taxonomies and utilizing insights from social constructionism, extensive work on citation has been carried out, especially reporting verbs within the research article (e. g. Swales, 1990; Thompson \& Ye, 1991; Shaw, 1992; Thomas and Hawes, 1997; Hyland, 2000, 2002; Adel and Garreston, 2008).A second strand of research analyzed difficulties encountered by non-native writers regarding issues of plagiarism, textual voice, paraphrases and adopting a stance (e.g Pennycook, 1996; Groom, 2000; Borg, 2000; Peccorari, 2006; Petric, 2007; Bloch, 2010; Mansourizadeh and Ahmad, 2011; Kwan and Chan, 2014).It is almost axiomatic for every researcher on the $\mathrm{Ph}$. D.(and MA.) thesis to make a note of the scarcity of research in that area compared to the much more covered research articles should be concentrated on the shorter research articles first and only much later, and more reluctantly, on the $\mathrm{Ph}$. D. thesis. Studies dealing specifically with citation practices in the $\mathrm{Ph}$. D. thesis include Thompson's (2005) pioneering research which compared citation practices between the Department of Agricultural Botany and Agricultural and Food Economics at a British university. His work became a model of analysis for interdisciplinary studies of the genre (e.g; .Charles, 2006; Petric, 2007; Chen, 2009; Maroko, 2013; Samraj, 2008, 2013). Regarding the Literature Review Chapter, despite its centrality, it was believed to be a facile and ancillary part of the research (Boote and Beile, 2005: 6). Even the few studies there are ( e.g Hart, 1998; Ridley, 2000; Bunton, 2002; Turner, 2003; Slack, 2006; Kwan, 2006) have concentrated on the rhetorical organization of the $\mathrm{Ph}$. $\mathrm{D}$. theses. Though being the backbone of the Literature Review, hardly have any studies tackled the variations in citational behavior in this Section as compared to the discourse of the native speaker. The present study seeks to bridge that gap and builds on the work ofSoler-Monreal and Gil-Salom (2012) who compared densities and nuances of reporting verbs in the Literature Review Sections in the field of computing 
divided among Spanish and British graduates. Our focus in this study is, however, the Theoretical Framework Chapter in the discipline of Applied Linguistics theses produced locally by Sudanese scholars in comparison to their British counterparts.

The major context of this study is the theses produced in English at The University of Khartoum, Sudan's oldest institution of Higher Education. Despite mass Arabicization brought about by political upheavals during the 1990s, English remains the lingua franca of research at the University (Ali, 2016). These vicissitudes and economic constraints resulted in an influx of local post-graduate studies which mirrored a global explosion of doctoral education (Abdallah, 2005; Arabi and Ali, 2014). Yet, it could be argued that expansion of doctoral programmes has not been matched by a parallel effort at training and assessment of the quality of the writing produced. The difficulties in thesis writing have been underscored worldwide by a host of scholars (Dong, 1996; Paltridge, 2002; Charles, 2006; Jonasson and Billhult, 2013) who have highlighted various hurdles facing candidates. Indeed, Swales (2004: 102) notes the scanty attention devoted to thesis writing in guides to Ph.D. writing, on account of the daunting size of the corpora that render generalizations and analysis difficult. However, the fact remains that these linguistic features must be studied to provide models for novice non-native researchers. This is applicable to the feature of citation which is a fundamental, yet occluded (Peccorari, 2006), aspect of the Ph. D. thesis with the objective of sensitizing these candidates to the different realizations of citations and its relation to the various disciplinary contexts. Situating this research within the Sudanese context, studies on discipline- specific EAP are few and far between. They have been initiated by El Malik and Nesi (2008) who compared the ways in which Sudanese contributors to highly- referred international medical journals employed subtle but significantly different rhetorical devices from their British peers. A larger and very recent attempt by Ali (2016) found ample variations in the manner local Sudanese scholars employed metadiscourse to align with readers in six disciplines representing the continuum of academic tribes. Ali (2011), however, has undertaken an earlier, but more relevant, endeavor in which he compared citation patterns in $24 \mathrm{Ph}$. D. theses produced at the University of Khartoum and equally representing Geology, Geography and Applied Linguistics. The investigation has unveiled ample variations between the objective and cumulative Geology, on one hand, and the discursive and epistemologically-divergent Applied Linguistics. Also, administrative and academic observations regarding the anomalous status of Geography were vindicated by its respective citation figures. Another important study informing the present research is the exploration by Alhassan and Holi (2016) who have employed qualitative methods to probe the problems and challenges encountered in preparing Applied Linguistics Ph.D. theses at the University of Khartoum from the perspectives of candidates and supervisors. Two candidates and two supervisors were included in semi-structured face- to-face interviews on their perceptions of the hindrances related to Ph.D. writing. The students were generally resentful of scanty meeting times with supervisors, little individualized attention, lack of guidance and scarcity of resources. On the other hand, the low linguistic proficiency, lax study habits and encroachment of work on students' research were among the major concerns expressed by supervisors. It is obvious that a sense of dissatisfaction was exuded by both parties, and that a thicker (Geertz, 1983) investigation needs to be carried out with respect to this genre in Sudan. Indeed, the current investigation is a sequel toAlhassan and Holi's (2016) study and attempts to verify whether the above bleak picture of candidate-supervisor relationship is reflected in the linguistic quality of the Applied Linguistics Ph.D. theses produced, as manifest in the cardinal feature of citation. More specifically, this study endeavors to explore and contrast the manner in which Sudanese and British Applied Linguistics Ph.D. candidates have employed the various subsets of citation in the Literature Review chapter of their respective theses.

\section{Methodology}

\subsection{The Corpus}

The corpus comprises $20 \mathrm{Ph}$. D. theses, 10 out of which were written and defended at The Department of English, University of Khartoum, Sudan over the last two decades, and 10 produced and defended over the last decade at The Department of English and Linguistics at The University of Glasgow, Great Britain. Direct access was gained to the Sudanese theses at The Department of English, University of Khartoum, while the British corpus was downloaded from the electronic theses repository of The University of Glasgow. Care was taken to ascertain that the theses were written by native speakers, and in the case of the British corpus, the criterion of first names (e.g. Claire, Duncan, Wild and Owen, to cite some of the present theses writers) was employed. Both sets of theses were related to the realm of Applied Linguistics, as compared to kindred subjects such as English Literature. Broadly speaking, the topics of the Sudanese these were more orthodox, dealing largely with the theory of second language acquisition, communicative language teaching and vocabulary learning strategies. Regarding the British theses, they charted out 
new territories such as academic discourse and critical literacy studies, while a number of the theses were colored by their Scottish setting, dealing as they were with the diachronic development of lexical items such as color, ejectives or religious jargon in Old or early Modern English.

As a subsequent step, the chapters devoted to previous literature had to be isolated out for analysis. It was assumed that the Literature Review would follow immediately after The Introduction. In fact, this was true of all Sudanese theses which followed a modified version of the Traditional Simple macrostructure (Introduction, Literature Review Theoretical Framework, Methodology and Discussion) (Bunton, 2002), and of which the Literature occupied the second chapter. However, in the case of the British corpus, this pattern was followed in only three theses, while the other seven employed a topic- based heading for the chapters, which were usually long historical descriptions of discursive constructs. Taking this into account, the researcher exerted an effort to determine which of the preliminary chapter(s) constituted a review of related literature. It was also observed that the British theses were appreciably longer, with an average length of 340 pages compared to 260 pages for the Sudanese theses. Yet, it was found out that the Literature Review had a much greater significance for the Sudanese candidates, as confirmed by the fact that, on average, it constituted roughly $30 \%$ of the whole thesis compared to a mere average of $18 \%$ for their British counterparts. Indeed, in the latter, LRs are proportionately much shorter. To take examples from the Sudanese corpus, LR encompasses 100 out of the 281 pages in thesis (1) and 96 pages out of 287 for thesis (3) and 82 out of the 198 of thesis (8). That compares to a mere 30 out of 304 pages for the total British thesis (10), 56 out of the 350 pages constituting thesis (6) and 81 of the pages in thesis (5). The result is that the Sudanese LR has an average length of 76 pages compared to 60 pages for their British counterparts. However, this discrepancy of figures is largely compensated for by the fact that British theses typically employ a 12 in contrast to a 14- font for the Sudanese theses. Hence, the aggregate word count figures are not far apart, as shown by the total of 186.247 words in the British corpus, compared to 193.785 words for the Sudanese sample.

\subsection{The Citation Schemes}

A variety of systems were introduced to analyze citations and their related features. First, following Swales (1990:141), citations were broadly divided into either non-integralor integral forms. In the former, the citation is separated from the sentence by brackets and plays no explicit grammatical role in the sentence. As for integral citations, they tend to highlight authors by including citation details within the reporting structure. Likew ise, the manner writers choose to incorporate others' work into their argument, ranging from extended discussion to mandatory acknowledgement, can have an important impact upon the expression of social relations. The choices in which reference portion duplicates the original material include brief quotes of few words; considerable wording set in indented blocks; summary as an abbreviated statement from a single source, or a generalization, which is a statement of convergence from two or more sources.

\subsubsection{Non-integral Citations}

Non-integral or 'fact-prominent' citations (Weissberg and Buker, 1990) were further divided using Thompson's (2005) fine-grained distinctions into the following:

1. Source: The citation informs the reader where the information came from. Thus, the citation has the function of attribution. The information is contained in a proposition, rather than a single noun phrase. Here is an example from Sudanese Applied Linguistics thesis (1), abbreviated as (SA1):

The production rules are a proof of a natural and similar order hypothesis regarding developmental errors (Milon, 1974; Burt, 1975; Krashen, 1982; Makino, 1989).

2. Origin: This citation attributes the proposition to a source, thus indicating the originator of a concept, technique or model. This example from BA (10):

Oppositional discourse type in the form of an 'anti-language' (Halliday, 1978) people use present a conscious alternative to the dominant or established discourse.

3. Reference: The citation refers the reader to a text to find further details, usually using the word "see". Here is an example from British Applied Linguistics Thesis 8(BA 8):

Cognitive linguists, and in particular cognitive semanticists, view speaker meaning as central to language; therefore, forms of 'figurative' language (see Preface, Lakoff \& Johnson 1980: ix-x).

4. Exemplification: The citation provides a number of examples of studies. Here is an example from BA (3): 
Although there is research(e.g. Brindely, 1984; Willing, 1988; Nunan, 1989; Richards and Lockhart, 1994; and Bada and Okan, 2000) investigating students' and teachers' attitudes,, there is little explicit examination of.....

5. Identification: The citation identifies an agent in the sentence, where the actor is either explicitly or implicitly included. Take this example from SA (8):

It was suggested (Tarone, 1983; Zolb, 1984; James, 1998) that linguistically unmarked items tend to transfer more easily than marked ones.

\subsubsection{Integral Citations}

Integral citations appear within the sentence in the form of a noun followed by the year number; typically the name will be incorporated into the sentence as an integral part of the syntax of the sentence and will not be separated by brackets. They are divided into the following categories:

1. Verb-controlling: This form of integral citation is contained within the sentence and controls a lexical verb. This type can be subdivided into either

a) Subject position as in this example from BA (9);

Claridge (2000:208-10) briefly analyzes Johnson's treatment of multi-word verbs, including phrasal verbs.

b) Passive construction, as in BA (7);

It was also established by Niedzielski (1999) that social information can

impact upon listener processing of phonological space.

2. Naming structure or adjunct agent structure. In this type, a noun phrase or an adjunct structure initiate the citation structure, as these two examples illustrate:

Lewis' $(1993,1997)$ work was important in establishing the centrality of lexis to language teaching. (SA2).

According to Pienemann (1988), a learner may learn a structure at stage $(X+3)$ if he is currently at stage $(X+2)$. (SA7).

3. Non-citation, where the citation is not accompanied by the proper reference details. This example from SA (3) illustrates this:

William Brumfit encourages relating linguistic structures to their communicative functions.

\subsection{Reporting Verbs}

Reporting verbs encompass a wide array of lexical devices writers employ to establish the credibility of the reported claims, espousing stance and indicating their attitudes regarding their propositions to their readers (Bloch, 2010; Hawes \& Thomas, 1994; Hyland, 2002; Thompson \& Ye, 1991). The reporting verbs within integral citations have been divided into the following processes and degrees of evaluation, based on Hyland's (2002) classification, itself a refinement of Thompson and Ye (1991), and Hyland's (1999) earlier version. The processes include the following:

a)Research Acts: These verbs represent experimental or real-world activities. They can occur in statement of finding such as develop, solve, identify and corroborate, as in this example from BA (5):

Hargus, and Davis' (2002:43) found “considerable interspeaker variation in VOT and foperturbation............

Research acts can also include verbs indicating procedural aspects of Experimentation using such verbs as analyze, observe, conduct and report, as in this excerpt from BA (1):

Nwogu (1997) examines entire articles but chooses MRAs only from top journals such as The Lancet and New England Journal of Medicine.

b) Cognition Acts: These are concerned with the researcher's mental processes, as shown in such verbs as postulate, point out, think, highlight and doubt. Here is an example from BA (2);

Another revision by Kay (1975: 260) noted the presence of the category GRUE denoted by a BCT spanning both BLUE and GREEN. 
c) Discourse Acts: These are the verbs that involve linguistic activities that focus on the verbal expressions of cognitive or research activities. Instances include the verbs discuss, define, state and propose. Here is an example from BA (10):

Cohen (1983) claims that today's social-control talk is characterized by a reversal of the direction ............

Regarding evaluative categories, we have adopted a standardized version of Hyland (2002) original complex system. Hence, a stance can take the form of a non-factive verbs, where writers convey the cited information impartially and objectively using such verbs as describe, state, analyze and classify. Below is an example from SA (6):

Fathman and Precup (1983) carried out research on communicative strategies employed in informal settings.

Equally, writers can employ factives such as confirm, concur, establish, conclude and show to underscore their acceptance of the authors' results. , This is evident in SA (10);

Gian (2002) demonstrated that a diminished vocabulary size will hamper students' comprehension appreciation.

Moreover, writers can convey their uncertainty or withholding of commitment using tentativeness markers such as, indicate, imply, believe and speculate as in this example from SA (4):

Sawyer (1982), suggests that '[t] he fact that English and Danish are closelyrelated does not mean that......

Finally, counter-factivessuch as dismiss, overlook, criticize and ignore allow writers to impute objections or reservation to the original authors. Take this example from BA (9):

However, Schmidt (1994) disputes Hargreaves (1990)' rationale in her analysis of the same problem.

\subsection{Procedures}

To count citations, each text was first stripped of all graphs, tables, diagrams, etc. and all the texts associated with them. Then each thesis was counted manually, taking co-textual clues into account. Next, Hyland's (2000) criteria were employed to pinpoint canonical citation forms such as a data in brackets, a number in squared brackets and Latinate reference to other citations. Reference to specific schools (e.g. Nativists, Neo-Firthians, etc.) were excluded, but a continuation of an argument by the author even when there is no mention of year was counted a valid citation, as were the cases when a date is attached to an author, even though the overall reporting structure is erroneous. Self-citations which, according to Hyland (2001), have other functions and are far less central to the academia, were also excluded. As a pre-requisite for the examination and comparison of citation features through the above classification schemes, all the instances of citation in the two corpora were quantified. While most of the taxonomies presented no difficulties, there were few cases of ambiguities regarding categorization of reporting verbs such as $u s e$, report and observe including more than one denotative activity, and here they were assigned their more contextual functions. Hence, the three were classified as, discourse rather than research procedural or finding research verbs, taking into consideration the verbal nature of the field of Applied Linguistics and its concern with terminological subtleties. Once the above validated schemes have been applied and the overall citation instances quantified as per 1000 words, appropriate bar charts, tables and figures forthe different citation classes have been produced for the purposes of comparison. Finally, Hyland's (2002) convention of referring to the producer of the thesis text as the writer and to the original cited person as the author will be retained in the present study.

\section{Findings}

The comparison of employment of citation in the two corpora subsumes many aspects. These will be outlined together with their statistical accompaniments, while the in-depth discussion of overall patterns will be deferred to the next Section.

\subsection{Citation Density}

The Sudanese corpus has yielded 5215 cases of citations in 193,785, corresponding to 520, 1 per LR Section and 26, 9 per 1000 words. These figures compare to a total of 4022 citations (402, 2 per LR chapter and 21,6 per 1000 words). While the density diverges significantly in favor of the Sudanese corpus, it is evident that LR chapters in both corpora are replete with citations. The statistics far exceed the average of 14, 8 per 1000 for whole theses in Thompson's (2005) study of the comparable Food and Agricultural Economics. Equally, the British corpus contains roughly twice as many citations as the ratios of 10,3 and 10,8 in Hyland's (2002) study of Applied Linguistics 
Research Articles, and the citation subset of metadiscourse in his 2005 study of Applied Linguistics post-graduate British theses respectively. Likewise, the figures of Sudanese LRs far outstrip the ratio of 17,3 per 1000 words found in Ali's (2011) corpus of whole Applied Linguistics theses.

Table 1. Average Citations

\begin{tabular}{lcc}
\hline & Sudanese LRs & British LRs \\
\hline Word Counts & 193,785 & 186,247 \\
Total Citations & 5215 & 4022 \\
Average per Thesis & 520,1 & 402,2 \\
Average per 1000 Words & 26,9 & 21,6 \\
\hline
\end{tabular}

One explanation for this concentration may have to do with the nature of Applied Linguistics as a re-iterative field concerned with building models out of existing literature. This entails, according to Thompson (2001:117), a thorough investigation and evaluation of the literature review in order to identify commonalities and differences. In this complication paradigm characterizing social fields, the LR assumes a prime place as a contested ground, after which there is not much need to resort to citations, as was clear from Thompson's (2005) study of final chapters in Food and Agricultural Economics ( and as we can only assume for this corpus which is confined to the Literature Review). An equally plausible explanation for the condensation of citations is the inter-disciplinary nature of Applied Linguistics, which is an interface between language, social structures and human agency and, hence, borrows from kindred humanity and social fields. This is more marked in the British corpus, which is more abreast with current state of knowledge. Take thesis (6) which relates Foucault's sociological concepts of hegemony, orders of discourse and archaeology of knowledge to the analysis of discourse of inmates at a Glasgow prison. As for thesis (10), it employs the tools of archaeological material culture, Bibliometrics, histrocist knowledge accounts and Medieval Textology to evaluate the state of medical manuscripts in the late Middle Ages. Regarding thesis (8), it combines the concept of metaphor in stylistics, religious Heliography and Renaissance Studies to analyze Hymns of Travel between 1650 to 1800 . A final example can be gleaned from thesis (4) which relies on the Geographical subfield of Toponymy alongside New Histocism and Sociolinguistics to trace the influence Scandinavian of the eighth and ninth century had on place-names in Northern Britain. Given the epistemological complexity inherent in elaborating references to these areas, it is only natural that heavy use of intertextuality would ensue.

\subsection{Types of Citations}

Of the three main citation types, integral citations constituted the majority in both corpora, with the British corpus appreciably outstripping its Sudanese counterpart (72,7\% to $65,9 \%)$. On the other hand, the statistics for non-integral citations were approximate, while the Sudanese employed roughly twice as many verbatim quotation of original authors. Yet, the latter category does not specify whether this was in the form of short integrated or block quotations, and, indeed, the nature of such quotations will be re-visited later.

Table 2. Ratios of Citation Types

\begin{tabular}{lllllll}
\hline & \multicolumn{2}{l}{ Integral Citation } & \multicolumn{2}{l}{ Non- Integral Citations } & \multicolumn{2}{l}{ Quotations } \\
\cline { 2 - 7 } & no. & $\%$ & no. & $\%$ & no. & $\%$ \\
\hline Sudanese LRs & 3437 & $(65,9 \%)$ & 1236 & $(23,7 \%)$ & 542 & $(10,4 \%)$ \\
British LRs & 2924 & $(72,7 \%)$ & 893 & $(22,2 \%)$ & 205 & $(5,1 \%)$ \\
\hline
\end{tabular}

The propensity both corpora have for integral citations is consistent with related studies. Indeed, in both Hyland's (2002) study of, among others, Applied Linguistics Research Articles as well as Thompson's (2005) study of Agricultural and Food Economics, integral citations were found to account for approximately two-thirds of the data. In addition to being easier to handle, a strong impetus for employment of integral citation is the length at which it allows writers to discuss the author's propositions. This can be argued to be particularly significant in social fields which seek to bring human agency and intervention to the fore as essential components of only partially replicable 
experimental techniques (Hyland, 2006). Human judgment is also particularly relevant to the field of Applied Linguistics, which is premised upon a series of revolutions and counter-revolutions (Koerner, 1999), initiated by pioneers who re-formulate diverse earlier precursors into original theories that result in a paradigm shift (e.g. Transformational Grammar, Systematic Functional Linguistics or The Lexical Approach). In ways akin to the importance of patents and property rights in Biology, as noted by Hyland (2002), the once authoritative figures of Bloomfield, Chomsky and Halliday is yet another proof of this phenomenon, termed The Matthew Effect (Garfield, 1977). It describes the tendency for citations to be concentrated on canonical authors, on a par with the Biblical dictum that both wealth and poverty tend to accentuate ever more. It can be claimed that both the pervasive presence of celebrated linguists within a particular thesis and the integral positions they occupy as pivots of actions are proofs of these characteristics in Applied Linguistics.

\subsection{Non-integral Citations}

Deployment of non-integral citations accounts for roughly a quarter of overall features in both corpora, and is considerably less than the one-third ratio generally observed in studies of similar social disciplines. The current findings suggest that writers tend to discuss ideas at length, rather than highlight phenomenon and process attributed to their sources or the heritage of the discipline, as cumulative scientific fields tend to behave.

Sudanese

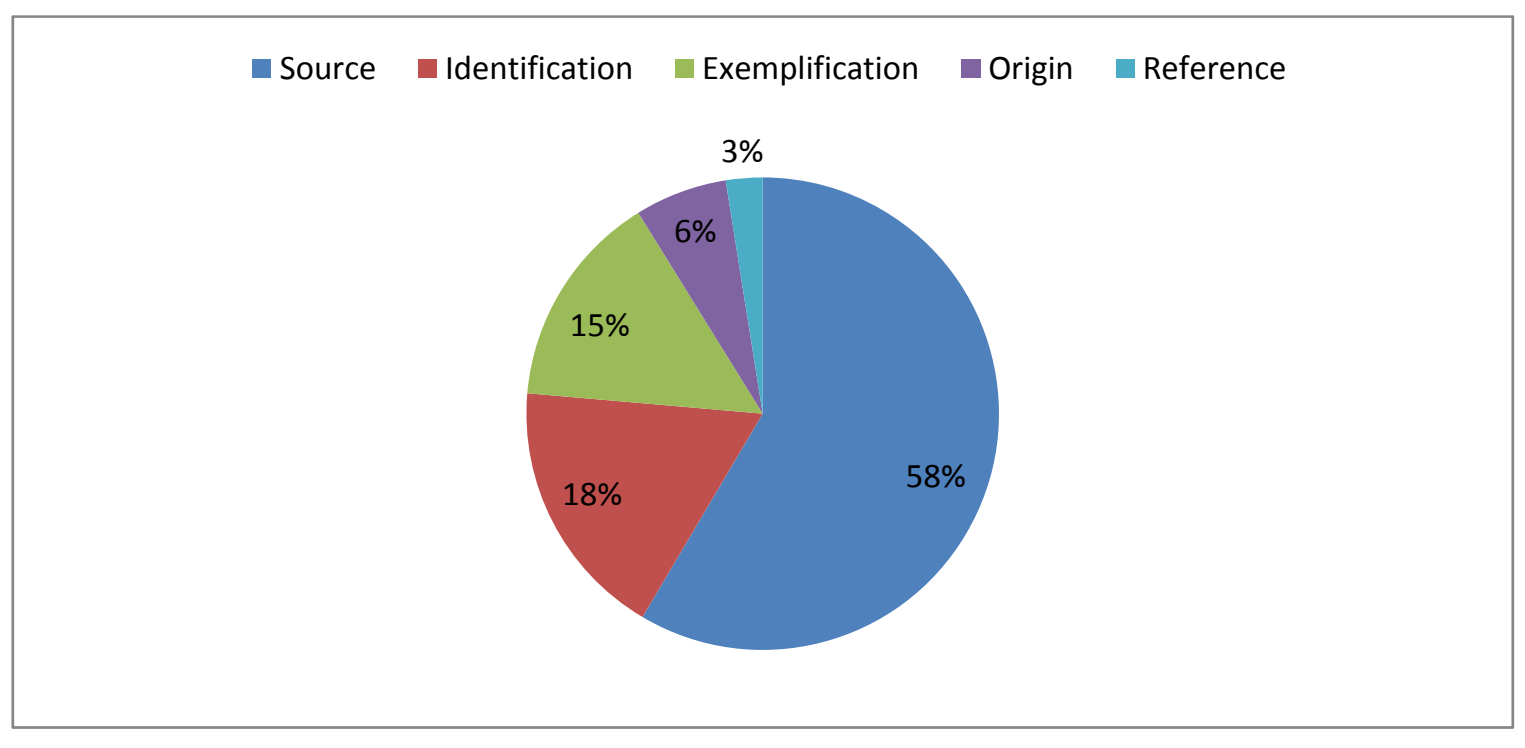

British

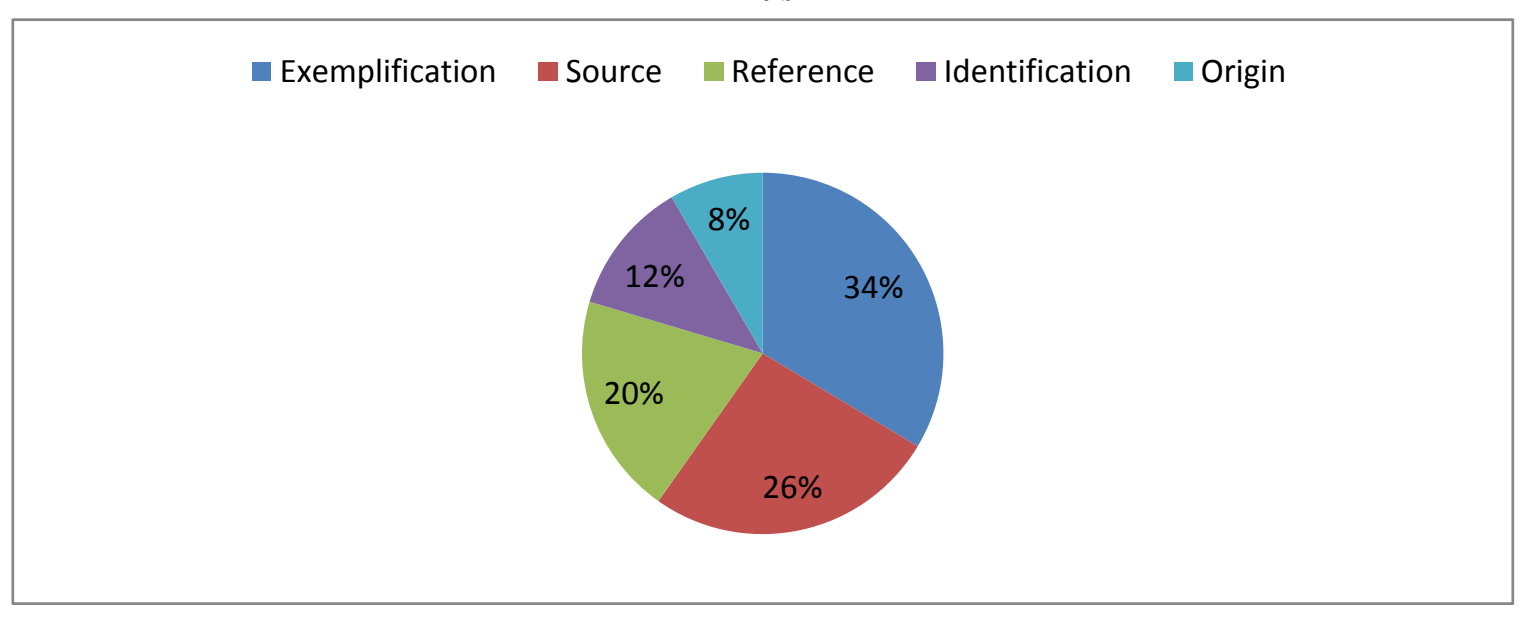

Figure 1. Types of Non- Integral Citations 
Regarding distribution of categories of non-integral citations, substantial variations exist between the two corpora. In the Sudanese corpus, out of the 1236 cases, Source comprises $723(58, \%)$ of the total. It is followed by Identification, which is essentially an attribution of information to a source involving an agentivity element, ranks second with 221 cases (18\%). Exemplification was moderately used and accounts for 183 cases (15\%). Finally, Origin ranks fourth with a total of 78 cases (6\%), whilst Reference citations are hardly employed (a mere 31 cases, or 3\%). Non-integral citations constitute only a slightly larger proportion of the total British corpus, but they are more evenly distributed among the five categories. Of the 893 occurrences, the largest share is claimed by Exemplification (300 cases, 34\% of total). References comes second with 234 cases (26\%), followed by Source (177, 20\%). Origin citations rank fourth (107 cases, 12\%), Identification occupying the last rank $(75,8 \%)$. The implications of the divergences in the two corpora will be dealt with in the Discussion Section of this article.

\subsection{Integral Citations}

As the Table illustrates, integral citations can be nominal or verbal in structure. With respect to the former, they make up only a fraction in both corpora, with the British employing modernly more nominal citations than their Sudanese counterparts (16,3\% to $12,5 \%)$. Much more intriguing are the verbal citations, which constitute over two-thirds of both corpora and are turn divided into active and passive constructions.

Table 3. Types of Integral Citations

\begin{tabular}{llllc}
\hline & \multicolumn{2}{l}{ Sudanese Theses } & \multicolumn{2}{l}{ British Theses } \\
\cline { 2 - 5 } & no. & $\%$ & no. & $\%$. \\
\hline Naming & 560 & $(16,3 \%)$ & 366 & $(12,5 \%)$ \\
Active & 2389 & $(69,5 \%)$ & 2199 & $(75,2 \%)$ \\
Passive & 268 & $(7,8 \%)$ & 295 & $(10,1 \%)$ \\
Non- Citations & 220 & $(6,4 \%)$ & 64 & $(2,2 \%)$ \\
Total & $\mathbf{3 4 3 7}$ & $\mathbf{1 0 0 \%}$ & $\mathbf{2 9 2 4}$ & $\mathbf{1 0 0 \%}$ \\
\hline
\end{tabular}

It can be argued that the ratios of active to passive is approximate in the two corpora, with an overwhelming preference for the active voice. Though not shown here, over two thirds of verbal citations combine a present simple tense with an active voice to provide a perennially fresh and animating air to discussion of writers' perspectives. Likewise, as in such studies as those of Malcolm (1987), Shaw (1992), Thomas and Hawes (1997), Hyland (2002) and Thompson (2005), the second tense category was the past simple, used to narrate experiments and studies conducted in the past in a social field like Applied Linguistics. Finally, non-citations can occur as a lapse when dealing with frequently cited authors. Their ratio of 64 cases $(2,2 \%)$ in the British corpus is acceptable, compared to their Sudanese counterparts who have thrice that number (220 occurrences, 6, 4\%). It is important to note that the Sudanese corpus contains many instances of miscitation of sources. While these were regarded as valid for purposes of quantification, their pedagogical significance will be dealt with later.

\subsection{Reporting Verbs}

In the previous section we have touched upon verbal reporting structures as related to their voice and tense. This part is devoted to a more thorough discussion of verb use in the two corpora, as below.

\subsubsection{Denotative Categories}

The analysis is based on Hyland's tripartite division of reporting verbs into Discourse, Cognition or Research categories. The latter comprises both Finding and Procedural research verbs. Below are the statistics for each of these:

Table 4. Denotative Functions by Category

\begin{tabular}{ccccc}
\hline Category & \multicolumn{2}{c}{ Sudanese Theses } & \multicolumn{2}{c}{ British Theses } \\
\cline { 2 - 5 } & no. & $\%$ & no. & $\%$ \\
\hline Discourse Acts & 1692 & $63,7 \%$ & 1484 & $59,5 \%$ \\
Cognition Acts & 317 & $11,9 \%$ & 257 & $10,3 \%$ \\
Research Acts & 648 & $24,4 \%$ & 753 & $30,2 \%$ \\
Total & $\mathbf{2 6 5 7}$ & $\mathbf{1 0 0 \%}$ & $\mathbf{2 4 9 4}$ & $\mathbf{1 0 0 \%}$ \\
\hline
\end{tabular}


The figures corroborate the initial anticipation that Discourse verbs would constitute the bulk of reporting structures. This is consistent with the discursive nature of Applied Linguistics as a discipline where explicit interpretation, speculation and argumentation are considered the customary modes of knowledge. The preponderance of textual processes and the rather unexpected dearth of Cognition Acts in both corpora are congruent with the figures in Hyland's (2002) major study as well as more recent investigations of English-related post-graduate research such as that of Vietnamese students by Loan and Pramoolsook (2015). Finally, the present corpus receives evidence of moderate use of Research Acts from related studies (Hyland has figures of 30,5\% for this category). A plausible explanation for the relative frequency of Research Acts is the dominance of the Finding subcategory (constituting roughly $59 \%$ of Sudanese Research Acts and 53\% of their British counterparts). Finding-related verbs are crucial in delineation of previous studies which constitutes a cardinal part of The Literature Review Chapter.

\subsubsection{Evaluative Functions}

As stated earlier, evaluative functions attribute a position or a stance to either the original author or writer of the thesis. The former are termed "Author Acts" by Thomas and Ye (1991), and are deemed to be the default mode of reporting in the statistics below:

Table 5. Evaluative Functions in Sudanese Theses

\begin{tabular}{|c|c|c|}
\hline \multirow{4}{*}{ Discourse Acts } & \multicolumn{2}{|l|}{ Tentative $452(26,7 \%)$} \\
\hline & \multicolumn{2}{|l|}{ Factive $320(18,9 \%)$} \\
\hline & \multicolumn{2}{|l|}{ Non- Factive 834 (49, 3\%) } \\
\hline & \multicolumn{2}{|l|}{ Critical $86(5,1 \%)$} \\
\hline \multirow{4}{*}{ Cognition Acts } & \multicolumn{2}{|l|}{ Positive $64(20,3 \%)$} \\
\hline & \multicolumn{2}{|l|}{ Tentative $128(4 \mathrm{o}, 4 \%)$} \\
\hline & \multicolumn{2}{|l|}{ Neutral $93(29,3 \%)$} \\
\hline & \multicolumn{2}{|l|}{ Critical 32(10\%) } \\
\hline \multirow{4}{*}{ Research Acts } & \multirow{3}{*}{ Findings $383(59,2 \%)$} & Factive $203(53 \%)$ \\
\hline & & Non- Factive $164(42,9 \%)$ \\
\hline & & Counter- factive16(4,1\%) \\
\hline & Procedures $265(40,8 \%)$ & \\
\hline
\end{tabular}

Table 6. Evaluative Functions in British Theses

\begin{tabular}{|c|c|c|}
\hline \multirow{3}{*}{ Discourse Acts } & \multicolumn{2}{|l|}{ Tentative $647(43,6 \%)$} \\
\hline & \multicolumn{2}{|l|}{ Factive $358(24,2 \%)$} \\
\hline & \multicolumn{2}{|l|}{ Non- Factive $322(21,7 \%)$} \\
\hline & \multicolumn{2}{|l|}{ Critical $157(10,5 \%)$} \\
\hline & \multicolumn{2}{|l|}{ Factive $78(30,4 \%)$} \\
\hline \multirow{3}{*}{ Cognition Acts } & \multicolumn{2}{|l|}{ Tentative $89(34,5 \%)$} \\
\hline & \multicolumn{2}{|l|}{ Neutral $65(25,4 \%)$} \\
\hline & \multicolumn{2}{|l|}{ Critical $25(9,7 \%)$} \\
\hline \multirow{4}{*}{ Research Acts } & \multirow{3}{*}{ Findings $401(53,2 \%)$} & Factive $232(57,8 \%)$ \\
\hline & & Non- Factive $125(31,2 \%)$ \\
\hline & & Counter -factive $44(11 \%)$ \\
\hline & Procedures $352(46,8 \%)$ & \\
\hline
\end{tabular}


Since Discourse Acts are the presumed medium of argumentation in Applied Linguistics, they will be our chief concern here. It is highly significant that roughly half of Discourse verbs (834 out of the total 1692) report verbal processes neutrally with no intervention on the part of the thesis writer. In fact, this phenomenon cannot be dissociated from the choice of verb clusters in Sudanese these, as we will observe in the Section below. It is also bound up with the conceptions of the communicative function of The Literature Review as an essentially amassing of previous studies rather than a site of contested knowledge claims to be reviewed only to be refined and re-invented The choice of the Sudanese stands in stark contrast to the British corpus where there is more even distribution among the four subcategories. More significantly, 647 (43,3\% of the total 1484 Discourse Acts, which is twice as many as those of the Sudanese corpus) report information tentatively, thus withholding the writer's full commitment and opening an evaluative niche. Indeed, in the Discussion Section, we will dilate on the two conceptions of reporting by juxtaposing excerpts of the Sudanese and British LRs. The dichotomy of Discourse is mirrored to a lesser marked degree in Finding Research verbs. While Factive verbs imputing a positive stance are moderately more used by the British (232, 57, 8\% to 203,53\% of total Finding category), the picture is more accentuated when non-factive neutral verbs are considered. Once again, the Sudanese have a disposition to report research unambiguously and untainted by personal judgment (164, $43 \%$ to $125,31,2 \%$ of total). Though the British moderately outstrip the Sudanese regarding Procedural Research Acts (46,8\% to 40,7\%), this information is largely vitiated by the fact that Procedural verbs carry no evaluative value or clue (Hyland, 2002)More significant is the use of Critical Discourse and Counter-factive Research, which are, again, twice as much employed in the British corpus. While this indicates more willingness to direct criticisms and rebuttals, it is important to determine whether the thesis writers bear the responsibility for these claims or imputes them to the original authors. Indeed, the distinction between Author and Writer Acts will be illustrated in the Discussion, as it is closely related to the requirements of the Literature Review itself.

\subsubsection{Distribution of Reporting Verbs}

As mentioned earlier, the Sudanese corpus contained 2657 instances of reporting verbs compared to 2494 cases for the British corpus. In confirmation of contrastive citation studies (Pickard, 1995; Groom, 2000; Pecorari, 2006; Soler-Monreal and Gil-Salom, 2012; Loan and Pramoolsook, 2015), the Sudanese and British students were found to employ different patterns of reporting verbs (a total of 156 for the former compared and 111 for the Sudanese. It appears that the British scholars had a wider inventory of verbs to draw from. On one hand, the two corpora had in common an overlapping core set of verbs (e.g. state, show, define, investigate and suggest, for example, though to varying degrees) On the other, extremely rare verbs as intimate, tackle, signalize, propound, adhere, resort, plot and register as well as moderately frequent ones such as posit, enunciate, concur, endorse, conceptualize and concede were more likely to occur (and be more effectively employed) in the British corpus. While there is an element of idiosyncrasy to the choice of reporting verbs, pedagogical considerations are even more important. The question of whether the use of reporting verbs is semantically and rhetorically adequate will be discussed through comparing extracts of the two corpora in the Discussion section of this article.

Table 7. The Most Common Verbs in the Two Corpora

\begin{tabular}{lcclcc}
\hline Sudanese LRs & no. & $\mathbf{\%}$ & British LRs & no. & \% \\
\hline 1. state & 270 & 10.1 & 1. suggest & 207 & 8.2 \\
2. propose & 234 & 8.8 & 2. believe & 174 & 7.0 \\
3. argue & 215 & 8.0 & 3. discuss & 159 & 6.3 \\
4. define & 180 & 6.8 & 4. argue & 135 & 5.4 \\
5. conduct & 167 & 6.2 & 5. report & 113 & 4.4 \\
6. suggest & 152 & 5.7 & 6. find & 105 & 5.2 \\
7. point out & 137 & 5.1 & 7. describe & 92 & 3.9 \\
8. find & 121 & 4.6 & 8. state & 81 & 3.2 \\
9. investigate & 110 & 4.1 & 9. conduct & 75 & 3.0 \\
10. claim & 93 & 3.7 & 10. point out & 69 & 2.8 \\
Total & 1679 & $63,1 \%$ & Total & 1210 & $48,5 \%$ \\
\hline
\end{tabular}


The total range of verbs was approximate, but the Sudanese scholars seemed to rely on a much more restricted set of reporting verbs. Hence, the most common 10 verbs in the Sudanese corpus constituted 1679 (63,1\% of total), as compared to 1210 (48,5\% of total) for the British corpus. Indeed, the Sudanese corpus is characterized by systematic inadvertent repetition of the same verb form. Thesis (6) has 23 consecutive cases of point out, while Thesis (9) 45 uninterrupted cases of define and Thesis (5) employs 27 cases of conduct over ten pages of Previous Studies. Comparing the two repertoires, they reflect both the heavy reliance on Discourse Acts, more specifically the neutral reporting mode of the Sudanese and the more ambivalent style of the British. On the other hand, it is the concentration of Finding and Procedural verbs that binds the two corpora. Yet, it must be said that of the two, it is the British who are closer to replicating the typical descending density of this discipline, as reflected in Hyland's (2002) study where argue, suggest, show, explain, find and point out were the most frequent reporting verbs.

\section{Discussion}

Review of Related Literature is a mandatory element of all doctoral research and Move structures. Yet, as Boote and Gaudelli (2002) point out, it assumes a greater significance within Educational fields (including Applied Linguistics) where there are dispersed knowledge strands and diverse audience, unlike natural scientific fields with their positivistic and widely shared knowledge canons. Since previous literature is embodied in the heritage of the discipline, utilizing these sources typically takes the form of manifest intertextuality. In both corpora, there is a condensation of overt citation, but it must be ascertained first that they meet the formal criteria of proper citations. While a small proportion of British citations omits full details, there are three times as many cases of non-citation in the Sudanese corpus. Inadvertence or the sheer number of repeated citations may be responsible for this, as illustrated by the following two examples:

Cowie's study offers a detailed description of the place of collocations in a learner's dictionary. (SA9).

Fallon identifies a number of hurdles in classification of ejectives. (BA10).

A much more problematic issue concerns miscitations, or cases where the citation does not conform to the APA style expected in Applied Linguistics. It must be stressed this applies only to the Sudanese corpus, as the British scholars generally handle formalities of documentation properly. There are countless and systematic cases of miscitation in almost all of the theses (accounting for 433 or roughly $10 \%$ of the corpus). Take examples together with the original wording from thesis (4) which contains 66 such features, which are indicated by asterisks:

*Students need not only have knowledge of the target language; they must apply this knowledge to negotiate meaning (Diane Larsen-freeman 1986).

*John Keith and Keith Morrow (1983) believe that when we communicate, we accomplish functions.

While miscitations are pervasive in the Sudanese corpus, thesis (8) is another systematically disorderly notoriety, where there are 124 cases of the type below:

*According to Graubery (1971: 217), in James (1980), English students of German.

Thesis (3) is an exceptionally systematically ill-cited research with such forms amounting to 80 cases, as below:

*Phil Wankat (1997) goes even further by saying that "Anything you can do in a large class......

*Speech styles are composed of subject matter, audience and occasions of formality. (Martin Jones, 1978).

In addition, there are innumerable occasions in the Sudanese corpus on which the citation is correct but awkward or inappropriate. Take the example of sprawling integral citations, where the non-integral could have been more natural. Only thesis (6) is free from this grossness. Space allows for only two examples:

Moreover, Vale and Peunteun (2001), Randell and Thomto (2001), Nikolov and Curtain (2000), Malderez and Bodoczsky (1999), Ur (1991), Krai (1993) Sullivan and Higgins (1983) emphasize teacher knowledge of linguistics................. (SA5).

Lexical studies on idioms were carried out by McMordie (1968), Makkai (1972), Mackin (1978), Seidl (1978), Alexander (1984) (1984a), Alexander (1984b), Baker (1992), Mola (1993) and Bessmertiyi (1994).

(SA9).

Furthermore, the Sudanese corpus is much more characterized by the tendency to latch onto one pattern of citation over many pages. To take two examples, Thesis (7) presents an extreme case of idiosyncrasy, where the writer utilizes the adjunct structure $T o X$.... as its primary citation style, with over 90 consecutive cases, as below: 
To Foto (1994), C-R activities

Normal times RomanTo Willis and Willis (1996:70), decontextualized texts can......

To Celce-Murcia (1979:20), GTM is........

To Sharwood Smith (1988), diagrammatization provides....

Equally, the adjunct integral according to could be overdone, as in AL (4) where there are 27 such cases in a course of six pages:

According to Krashen (1981), there is a distinction between .......

According to Lennerbers (1967), brain plasticity is lost at puberty....

According to Cleason and Ratner (1998), the theories of L acquisition must account. ....

According to Chomsky (1965), innate biological mechanism is related to ....

According to Pavlov and Thorndike (1928), it is possible to predict language learning by .....

Probably, Sudanese scholars' mishandling of citation is nowhere more manifest than in their quotations. We have already seen that quotations account for a tenth of all Sudanese citations, twice as much as their British peers. Yet, it is the quality of the former that is our target of criticism. Many of these citations can extend over eight or even ten lines. Despite the fact that advice is to use verbatim quotation only when the author's original words give the maximum effect, the Sudanese use them naively, extensively and uncritically. This feature afflicts (my emphasis) every thesis in the Sudanese corpus. To illustrate this, we will reproduce two excerpts typical of the Sudanese corpus and juxtapose them against two quotations by British academicians. The first is taken from Thesis (3) and contains nothing vivid or memorable, and its listing of facts could have better been paraphrased:

Swan (1996:1) referred to all those interested in learning English worldwide as speakers of English:

People learn English in different parts of the world, under different conditions and for different purposes. Many learn English as their mother tongue. There are between 320 and 377 such people, depending on whether English is treated and whether creoles are included. However, most people who speak English have learned this language alongside another language, whether as a second language (about 150 to 300 million) or foreign language (about one billion). It is these two groups of speakers for whom English is not the mother tongue who have given English its current status as an international language.

The second excerpt is from Thesis (1) and contains a number of unanalyzed and unintegrated quotations, exemplified by the first two:

Savington (2983) characterizes communication similarly as follows:

It is dynamic rather than static. It depends on the negotiation of meaning between two or more persons. It is context-specific, as communication takes place in a in an infinite variety of situations, and success in particular roles depends on one's understanding of the context and on prior experience of a similar kind.

And Krashen (1986) who discusses of communicative interaction echoes these notions:

Interaction always entails negotiation of meaning i.e adjusting one's speech to the effects one intends to have on the listener. It entails anticipating the listener's response and possible misunderstandings, clarifying one's own and the other's intentions and carrying at the closest possible match between intended, perceived and anticipated meanings.

Compare the above successive and unwarranted quotations to this piece from British Thesis (5), drawing on the famous Orwellian dictum:

Power distance - the degree to which a society accepts the idea that power is to be distributed unequally.Space As Hofstede (1980: 136) notes, 'All societies are unequal but some are more unequal than others...

Or, alternatively, take the more extensive quotation from British Thesis (2)::

Before Berlin and Kay (1969), domain of color was taken as a prime example of the arbitrary nature of meaning as the following statement from Bloomfield's (1933) classic textbook demonstrates:

Physicists view the color spectrum as a continuous scale of light waves of different lengths, ranging from 40 to 72 hundred-thousandths of a millimeter, but languages mark off different parts of this scale quite arbitrarily and without precise limits, in the meaning of such color-names as violet, blue, green, yellow, orange, red and the color names of different languages do not embrace the same gradations. (1933: 140). 
Clear distinctions are also found in the two corpora with regards to general evaluation, which positively or negatively judges a sources, ranging from a word to a clause. In its simplest form, this can assert the value of a work as below:

The classic work on the history of attitudes towards the English language is Jones (1953), which provides a comprehensive survey of....... (BA7).

$D$ "Orsey (1842) is notable in that his is the only grammar to give a separate conjugation table for phrasal verbs. (BA8).

Posteguillo's study (1999) was instrumental in helping me to understand that some... (BA1).

Malcolm's (1998) book is probably the most extensive study regarding societal values

A parallel example from the Sudanese corpus is below:

Nation (1990) is credited with establishing the first reliable vocabulary breadth testing tools. (SA10).

However, the statistics reveal that in 34 out of 43 such cases, the Sudanese scholars predominantly praise the author rather than his work, which fact is considered by Rose (1996) as a mark of a novice researcher even for a Master, let alone, a Ph.D. candidate: The effect is aggravated by the poor linguistic structure. The fascination with prominent linguists in the Sudanese corpus is probably to the pedagogical atomistic legacy of Structural and Chomskyan linguistics until recently glorified by the syllabi (Abdalla, 2005) which have only lately been replaced by communicative language teaching. Indeed, three out of the ten theses were devoted to CLT, and it was natural only that figures like Chomsky, Hymes and Widdowson should be lavishly either praised or denounced. Four theses devoted to Error and Contrastive Linguistics, which, again, are implicated with Structuralism, Behaviorism or Generativism. This applies too to the "lexical turn" manifest in the remaining three theses. Hence, the figures of Chomsky, Nation, Corder. Ellis, Selinker and Krashen cut across many theses. In fact, the Sudanese theses read strikingly and suspiciously similar To sum up, the Sudanese corpus is distinguished by a limited stock of authors who are heavily cited and who are invested with a hallowedness reflected in the naïve evaluations below.

Selinker (1972), the important author, tried to capture the interaction between L1 and L2. (SA1).

Nunan (1988), who has successfully contributed to the field of Education, define a syllabus as..............

(SA2).

The well-known communicative writer Savington (1988) describes communication as .....(SA5).

Krashen (1972), a famous second language acquisition researcher, shares somewhat Lennenberg view...

(SA6).

Reporting verbs is another thorny issue for Sudanese scholars. Indeed, there are countless examples in the Sudanese corpus where the vocabulary used in reporting structure is erroneous. While the examples abound, the verbs "see" and "say" are ubiquitously used to the wrong effect, as in these representative instances:

*Richard and Rodgers (2001) see LPR as a reflection of ..... (SA7)

*.Singleton (1999:12) sees that phonetic characterizations of ....... (SA10).

* Sharwood Smith sees the teaching of grammar as a route to CC. (SA3).

*Wilson and Anderson (1989) say that schema theory provides ideational scaffolding in.......... (SA4).

*Spolsky (1989) says "Whatever the language learner brings to the task......"(SA8).

In fact, misuse of "see" for "view" and "say" for "write" is endemic in all theses and occurs on no less than a hundred occasions. The representative semantically erroneous reporting verbs below are only a fraction of the total errors, and should have been replaced by "reject", "concede", " comment", "contends", "develop", "note" and "reiterate" respectively.

*Bley-Vroman (1990) refuses the assumption that .......(SA1).

*Brown (2007:264) confessed that less proficient students rely on transfer than proficient ones. (SA8).

*Yule (1983a) remarks that language has two functions............. (SA3).

*Widdowson (1992) contents that cultural knowledge is important in ...... (SA4).

*Schmitt (2001) has evolved a computerized system to measure word association. (SA10).

*Nesselhauf (2003) notices there is a thin but important distinction between collocations and fossilized expressions. (SA2). 
*Politt (1991:53) confirms the same explanation by saying that idioms..... (SA5).

One more problem related to reporting verbs is lack of variety and use of undifferentiated stock of verbs regardless of textual and disciplinary contexts. A glimpse of this was obvious in the high proportion $(63,2 \%)$ occupied by the most frequent ten verbs in the Sudanese corpus. The haphazard manner in which the Sudanese scholars alternate their use of verbs is indicated by the following piece from Thesis (4):

The relationship between language of culture was first debated in the Eighteenth century. Kant (1781) originally argued that new concepts can have meaning only in relation to what the individual already knows.Carrell (1983) argues for the importance of cultural meaning for comprehension. This involves the ability to relate the textual material to one's schematic knowledge. In the same way, This view was pointed out earlier by Gassan (1984) who believes that language and culture are closely linked and that a citizen of of the world should know his cultural weaknesses and strengths. Daman (1987) points out that the teaching of culture is an important focus of classroom practice. Also, Foda (1994) makes the point that it is time to focus on cultural background knowledge in classroom activities, especially reading comprehension. In addition Podromon (1992) argues that knowledge of the target language culture is essential as it provides delight and enjoyment in an authentic manner. Likewise, Badrawi (1994) points out that interaction between the learner and the textbook is never complete without

This excerpt only provides a clue of a much more deeper and endemic problem in the Sudanese corpus, whose scale is revealed when whole theses are considered. It is almost certain, then, a pattern will emerge where every thesis writer has a finite list of reporting verbs (particularly state, argue, point out, suggest, conduct and investigate) that he alternates between automatically irrespective of the co-text or the rhetorical purpose, and which are reiterated in all the Sudanese theses.

Another essential issue in the Sudanese corpus concerns the lack of integration of cited perspectives within the writer's own discourse. This deficiency is inherent in the conception of the Literature Review itself, namely that it is a narration of diverse viewpoints and that it is the duty of the researcher to amass and collect. However, it is the perspective of the researcher that must be dominant. We will illustrate this by an excerpt devoted to the contribution of Stephen Krashen to Second Language acquisition from SA (7):

Prominent among teaching experts who have tried to answer that question was Krashen. At the beginning, Krashen (1982) strongly objected to any kind of explicit grammar teaching. He thinks that LGT leads to conscious knowledge which is useful to learners as a "monitor device"to check their production in the target language. Krashen claims even if learning takes place, only easy rules are thus learned. Nonetheless, acquiring language through 'creative construction processes' is seen by Krashen as more beneficial. To learn language in this way, Krashen (1982) advocates naturalistic exposure to the foreign language. This "comprehensible input" Krashen, assumes, is sufficient to help learners acquire the target language. Rutherford (1987) avoids talking of grammar teaching. Subsequently, Krashen modified his views on teaching grammar and suggested that formal classroom instruction can be effective, particularly in relation to adult EFL learners. In this respect, Krashen considers formal classroom environment to be of great value not only because it affords learned the opportunity for grammar instruction, but also because learners benefit from the comprehensible input.

In this excerpt, the writer is invisible, we do not hear his presumed proposition. He speaks on behalf of Krashen, more of a tabula rasa than a researcher advancing knowledge. Indeed, no analysis is offered of Krashen's ideas or how they relate to the writer's own point of view. It is a pattern replicated hundreds of times in the Sudanese corpus, in which the researcher is a passive recipient and transmitter of knowledge. Compare the piece above to the skillful manipulation of the variety of reporting verbs and strategies to serve the writer's evaluation of the cited material by the following British Thesis (8):

Reddy ([1979]1993) observed that, far from being 'semantically anomalous 'construction, metaphors are inescapable, and actually seem to provide the underlying structure for basic systems of thought. Specifically, Reddy discusses the ubiquity in English of a 'conduit metaphor' by which words seem to 'contain' ideas, feelings, and things, and to 'convey' them between people. Reddy shares some of the distrust for metaphor characteristic of the more traditional writers, and his account reflects a continued belief that figurative language obscures the 'true' nature of things. He claims that the reliance of the English language on the Conduit Metaphor can and frequently does have serious consequences: it has severely limited scientific and philosophical thought, has negatively affected government policy decisions, and has even promoted the gradual death of humanism as a valid philosophy. It might be objected that the 
conduit metaphor was presumably active during the rise of humanism as well; but Reddy's claims do recognize that metaphor can have a drastic effect on communication and thought.

Reddy personifies the English language as an 'evil magician' who seeks to control our thought processes and actions without our consent, with the ultimate goal of creating discord and discouraging cooperation in interpersonal communication. He calls for a general 'frame shift' in linguistic thinking - possibly involving 'a serious alteration of consciousness' (1993: 166)—which he believes will be necessary in order to perceive the 'new facts' about metaphor.

Reddy's construal of certain metaphors as insidious dangers to human society may seem implausible in light of the later observations of Lakoff et al (1999).: if metaphor is seen as a necessary component of both thought and language, then, like language in general, its effects can be positive or negative. However, Reddy's observation of the extreme degree to which conceptual metaphors affect and permeate a society is important and valid, and his new way of thinking about metaphor laid the groundwork for studies which, like the present one, study the interaction between metaphor and culture.

Note how dominant the textual voice of the writer here is. Reddy's ideas are explored at length, but only as a backdrop to the writer's own proposition on the interaction between metaphor and culture. Mark the dexterous use of observe and discuss as neutral textual verbs aiding the unmediated exposition. Equally significant is the transition to claim which opens an evaluative space and is a prelude to the writer's own objections to Reddy's Conduit Metaphor Theory. The writer employs another citation (Lakoff et al, 1999) to bolster his skeptical view (using seem) on the positive role of metaphor within thought. The writer concludes by revisiting Reddy's own contribution and wedding it to the reservations she has considered to provide the justification and new perspective for her thesis.

A citation is not commendable per se, but must be made to support, contextualize or instantiate aspects of the argument presented by the thesis writer. This is underpinned by the complementary terms averral and attribution, introduced by the Sudanese EAP author, Angela Tadros (1993:101). As expounded by Groom (2000), averral is the default condition of the written text, whereby the writer assumes the responsibility, while attribution is the acknowledgement of the source of information through citation from an author. Hence, a successful argumentation is one that positions the textual averred voice of the writer as dominant, while other attributed texts must be subordinate to that voice (Groom, 2000:19). Our discussion will be related to how far the two groups of writers utilize citations for ulterior purposes. It is significant that in a later article, Thompson, who has provided many of our models, has analyzed citations in terms of their writer-author responsibility. For examples, in both Source (an attribution of a proposition to a source) and Identification (an attribution in which the agent is implied), the writer endorses the proposition, and the textual responsibility lies with the author (Thompson, 2009:104). These two stand in contrast to the other three types of non-integral citations. According to Thompson (ibid), both Origin (a parenthetical posmodificatory relationship not referring to a proposition and Exemplification (a parenthetical relationship) carry the writer's averred implicit positive evaluation. On the other hand, Reference carries the writer's voice in the imperative See. Regarding integral citations, Thompson believes that Naming citations have a great variability and that Verb-controlling (including Discourse, Cognition and Research) vary based on the degree of evaluation conveyed. Let us compare these parameters to the data of the two corpora. Regarding non-integral citations, it is significant that Source and its kindred Identification comprise $76 \%$ of all Sudanese non-integrals compared to 38\% for the British, together with the fact that in the latter Exemplification and Reference constitute 54\% of all non-integrals. The greater variety of the British corpus testifies to more manipulation of textual material. This is particularly evident when considering Reference citations that constitute a fifth of all non-integrals in contrast to a mere 3\% for the Sudanese. Hence, examples as below are common:

Given current scholarly awareness of the pervasiveness of metaphor in language, it seems unwise to attempt to draw too sharp a distinction between the literal and the idiomatic (see also Claridge 2000:47; Hampe 2002:15-22). (BA2).

These citations reveal the breadth of knowledge writers have accumulated, but do not feel required in the research. By signposting readers to other sources, writers, among other things, display their discrimination of what is peripheral and what is substantial to the argument, as well as their grasp of the key texts they have digested and to which they refer their less informed readers (Howard, 2008:5). Equally, the British heavily relied on intra-textual ties both to build a network of endophoric markers to aid readers navigate the text, and to increase coherence through cross-reference to other parts of their theses, as exemplified below:

The negative-positive dimension was incorporated into the design of the responses required to statements concerning attitudes in the questionnaire, (see Section 4). (BA3). 
I have dealt with levels of generality above in Section 1.2; as mentioned there, (BA8).

All Verb-controlling/ reporting citations can either attribute a position to the original author (thereby absolving the Writer from responsibility) or aver the writer's stance and evaluation of the cited material. These two types are termed Author Acts and Writer Acts by Thompson and Ye (1991). Since a Literature Review is largely a compilation of previous sources, Author Acts are the overwhelming majority in both corpora Positive Author Acts are the norm, and so they have been, and will be, amply instantiated throughout this Section. We will complement them with negative reporting of another's work, using the medium of Author Acts. In both corpora, Critical Discourse verbs constitute the majority of cases, followed by Cognitive rebuttals, and only a few cases of Research Counter -factives:

In particular Voigts (1979:541) disputes Eisenstein's suggestion that vernacular Scientific writing developed because of printing. (BA9).

Barcelona (1993:22) denies the 'misleading view of a metaphor as some kind of deviation or aberration from proper usage. (BA8).

Foucault (1972) alleges that behind the language of penal reform there lies the 'will topower' a conception which..... (BA6).

The role of the Markedness theory was refuted by Ellis (1994). (SA8).

Rutherford (1987) questions whether the "common entities view" of language is workable despite its prevalence. (SA7).

As early as 1971, Hymes has attacked Chomsky's view of competence as.... (SA1).

Though much less common, Writer Acts reveal much more capacity to analyze, assess and even criticize the information rather than merely transfer the source, as in the case of Author Acts. Below are four of the scoreof positive Writer Acts in the Sudanese corpus:

To Dulay et al (1982), research shows that first language contribution to SLA may have to do with accent. (SA6).

Read's experiment (1989) suggested several valuable insights into designing and conducting interviews (SA10).

Irujo's (1986) study exhibits all the characteristics of idiomacy. (SA2).

Cazden et al's (1975) study confirms the supposition that learners...... (SA1).

Positive Writer Acts in the British corpus constitute a much larger set and employ much more sophisticated evaluation, Moreover, due to their greater involvement, the British scholars do employ Writer-oriented hedges (Hyland, 1996: 440-441). These allow writers to perform the dual function of placing their claims within a larger disciplinary framework and forestalling criticism and opposition through minimizing the degree of their commitments to their claims. According to Hyland (ibid), Writer-based hedges are associated with evidential verbs including appear and seem to bestow a degree of commitment to statements.). The instances below illustrate these tendencies:

The experienced and renowned phoneticians, Ladefoged and Johnson(2010:140) even attest to the difficulties faced by ....BA5).

Black's (1993) view of metaphor, while lacking an explanation for the extensive, cohesive metaphorical systems observed more recently by Lakoff and Johnson (see Section 1.2), shows the beginnings of a more general willingness to viw metaphors from non-constructionist perspective. (BA2).

Foucault's (1977) approach to discourse analysis merits attention for the following reason: his model is......... (BA6).

From Fullan's (1999) contribution regarding change there would seem to be little doubt that we need to know more about teachers........ (BA2).

The works of McConchie (1988) and Eamon (1994) also serve to illustratethe contentious position of English in medicine two centuries after the vemacularisation. (BA5).

Simpson's (2007 and 2010) study of ejectives in English, although not exclusively focusing on them in any English variety, do pertain to the language in general. (BA10).

Reporting on an experiment conducted in 2010, Pantos \& Perkins (2013)appear to have been the first to 
use auditory stimuli in an IAT ...... (BA5).

Yet, sadly enough, the whole Sudanese corpus only contains $78(2,3 \%)$ of these wholly positive Writer Acts, compared to 307 (12,3\%)of all cases for their British counterparts. The Counter-factive and Critical Writer Acts are non-existent in the Sudanese corpus, as contrasted to the numerous occasions on which the British bear the burden of sifting and weighing out the merits of the literature. Three judicious examples will illustrate this:

If Nicolaisen were correct in his assertions, then this would cast considerable doubt on the possibility that the inversion-compounds are.....(BA4).

The results of Berlin and Kay (1969) seminal work on colour universals presented a serious challenge to the prevailing relativist consensus on colour terminologies. (BA2).

Finding a means of categorization has proved problematic, as approaches which work for the early modem period, such as Slacks (1979) are not supported bythe surviving evidence from medieval. (BA4).

A crucial difference between the two corpora concerns the writer's intrusion in citational context. In fact, the British scholars freely employ the first person throughout their texts, unlike the Sudanese corpus where hardly any self-mention was made (a result consistent with the low ratio of 2,2 per 1000 occurrences found in Ali's (2016) study of Sudanese research articles). Though this serves to enhance their authorial presence and underscore the highly delineated and interpretive nature of Applied Linguistics (Hyland, 2001, 2004, 2005), it also better positions British writers to manipulate their citations in multiple functions, particularly elucidation of methodological underpinnings, as illustrated by the following examples:

Move Two in my framework mirrors Swales' (1990)second Move, of Establishing a niche(1990, p.142); however, in Swales' work, this Move is comprised of........ (BA1).

In this study I have adopted much of the 'ecological' approach to literacy laid out by David Barton (1994), which was further developed into what Barton and Hamilton later describe as a 'social theory' of literacy (2000,7). (BA10).

I am largely drawing on the concept of discourse provided by CDA, inparticular Fairclough's (1992) three-dimensional framework for discourse analysis. (BA6).

In comparison, the Sudanese texts seem to be dry, detached and impersonal. Indeed, in the majority of Sudanese theses, there is a duality between the discussion of theoretical concepts (as a passive reflection of what is found in the literature, (as we have seen in analysis of the reporting verbs) and the exposition of concrete studies, usually at the end of the Chapter. These experiments are treated as self-contained, self-sufficient and peripheral parts of the Chapter. Instead of being thoroughly discussed, compared and contrasted to underpin their weaknesses and strengths in order to indicate a niche, thisSection usually a perfunctory catalogue of facts intended to fulfill the formal requirements of the Ph.D. degree. Space allows only for an indication of the organization of this part. In this excerpt from Thesis (4), we have included only the author and the first line of the exposition (usually occupying half a page). The crucial point is that these studies are treated in turn and that no attempt is made to relate them to each other or to the writer's purpose.

Steffenson and Anderson (1979) reported a study that aimed to examine the impact of cultural knowledge on reading comprehension. In the study, two groups

Carrell (1987) investigated the simultaneous effects on ESL reading comprehension of both cultural and content schemata.. The study involved 28 Muslim.

Nunan (1991) investigated the influence of schematic knowledge on reading comprehension process of second language readers. His focus was

Ziddan (1994) conducted a study to explore areas of cultural conflict between two systems. Four hypotheses were formulated.

Straub (1999) designed a cross-cultural course for homogeneous Italian speakers. The study's purpose was.......

Compare the above shortened, yet, full-fledged excerpt above to the following final excerpt from British Thesis (1):

The studies by Nwogu (1997), Li and Ge (2009) and Kanoksilapatham (2005) identify three Moves in the Introduction section, similar to Swales' (1990) CARS framework. Li and Ge (2009) adopt Nwogu's (1997) Moves, but they note several changes concerning Moves that Nwogu had previously marked as optional. Nwogu (1997) claims that Moves One (Present background information), Six (Describe data-analysis 
procedures) and Eight (Indicate non-consistent observations) are optional, as they appear in fewer than $50 \%$ of the articles in his corpus. In their corpus of texts published between 1985 and 1989,Li and Ge (2009), using the same benchmark of 50\% for optionality, found the same Moves and that they were still not mandatory. However, in their corpus of texts published between 2000 and 2004, using the same benchmarks, they found that Moves One and Six were no longer optional but obligatory, and, while Move Eight remained optional, they added a ninth optional Move (Highlight overall research outcome). This shift in optionality of Move-assignment may reinforce the commonly held idea that genres undergo changes over time, and suggests that the time period in which the data are published or that the data represent needs to be included in the discussion of possible reasons for differences among studies. While each of the authors follows Swales' model of identifying Moves, they do not all identify the same Moves. Skelton (1994), Nwogu (1997), Li and Ge (2009), and Fryer (2012) look at corpora of MRAs, while Kanoksilapatham (2005) examines RAsin a different field or discipline. A possible reason for differences among Move assignments and whether the researchers consider the Moves to be optional or obligatory may be the different sizes of the corpora used or sampled by different researchers. In effect, the researchers have a threshold percentage to indicate whether a Move is obligatory or optional. The smaller the corpus, the more impact a Move has on the percentage, which may impact the findings of the smaller corpora when compared to the larger corpus (250 articles) that has been compiled for the current research.

The contrast could not be any starker between the two pieces. In a way reminiscent of their earlier exposition of theoretical constructs, The Previous Studies Section is a mere synthesis of studies, among which no chains or contrasts are established or, indeed, to the writer's arguments (all of which conditions are fulfilled in the British corpus). As in many previous cases, the Sudanese scholars are content with the mere imputation of studies to their originators rather than attempt an in-depth or critical analysis or appraisal. For Petric (2007: 248) this tendency towards descriptiveness is more befitting the Master degree where display of knowledge is a primary requirement. Ironically enough, the Sudanese are more conscious of the role of citations, as indicated by their higher ratio of 26, 9 as compared to 21, 6 per 1000 words for the British corpus. Yet, it is a negative awareness geared towards accumulating as many references as possible and presenting an evidence that they have consulted them. In fact, it is this knowledge-telling (Bereiter and Scardamalia, 1987) mode of learning that may be responsible for this patchy Literature Review termed by a late Sudanese professor named Al Busairy (personal communication) as a cut-and-paste writing strategy. Petric (2007: 249)) contrasts such an approach to the West-inspired knowledge transformation (Dong, 1996) as being crucial at the much more advanced level of the Ph.D. degree, where a citation must be for a purpose, as, indeed, it is the case for the above British scholar analyzing previous studies on Moves analysis in order not merely demonstrate his mastery of the literature, but also to elaborate his own Methodology (as indicated by the authorial presence at the very last line of the quotation). To sum up, the tenor of this discussion, the Literature Review of the Sudanese scholars is largely a synopsis of previous views and studies, delineated from the vantage point of the authors. Seen in this light, the Sudanese corpus lacks many of the qualities distinguishing a good Literature Review indicated by Boote and Beile (2005:4) such as the determination of what is relevant and what is irrelevant (remember the paucity of Reference citations in the Sudanese compared to the British who show much more discretion about which texts to analyze at length and which are tangential but had better be consulted at the reader's leisure). Equally, as we have seen, the Sudanese scholars largely lack the capacity to appraise and criticize the literature (both theoretical and practical), nor do they sift the literature to locate the shortcomings necessary to their indication of the novelty of their positions and, consequently, establishment oftheir contribution of new perspectives both to the theoretical underpinnings and refinement of existing methodologies.

\section{Conclusions and Implications}

Intertextually appropriating Donne's (1601) line "No Man is an Island", Widdowson (1993:27) declares that no text is an island. Indeed, the manner in which all language builds on, echoes, transforms or refutes prior discourse has increasingly been acknowledged in Post-struxtural theories (e.g Barthes, 1980; Kristeva, 1989, Fairclough, 1992, 1995) and has had far-reaching ramifications for the study of literature, Cultural Studies, Critical Discourse Analysis and Sociology of Knowledge. Yet, it can be argued that manifest intertextuality is most explicit in academic discourse in the form of overt reference to previous literature. In fact, employment of citations is almost synonymous with the functions of the academia, and since the ultimate objective of original research (such as the Research Article or the Ph.D. thesis) is the generation of new findings, this entails review of the existing literature in order to ground one's research in the heritage of the discipline as well as present the credentials of an expert member of the discourse 
community. Moreover, citations are required to delineate the latest advances in the field and, thus, demonstrate the novelty of one's position, which is also reflected in the need to assess the merits and shortcomings of current research prior to offering a justification for the researcher's endeavor. Finally, citations are crucial in both defending the validity of scholarly claims and, again, imparting a sense of continuity through re-contextualizing the results within the larger sanctioned disciplinary framework.

Being an essential aspect of academic discourse, the manipulation of the myriad functions of citation is an integral part of thesis writing, and can be a predictor of the quality of research produced, as indicated in the studies by Boote and Beile (2005), Petric (2007) and Howard (2008). However, there is evidence that citation is an occluded (Pecorari, 2006) feature of writing whose intricacy is rarely acknowledged or sufficiently covered in the literature on thesis writing in terms of the options at the disposal of the student and their relation to the epistemological conceptions of the different disciplines(Paltridge, 2002; Hyland, 2002; Swales, 2004; Swales and Feak, 2012). A further impetus for this study is the educationally ambivalent Sudanese context, where conflicting linguistic policies at the tertiary level were exacerbated by various financial, administrative and resource constraints. Part of these difficulties were uncovered by the study of Alhassan and Holi (2016) on the candidate-supervisor relationship at the level of the Applied Linguistics Ph.D. theses undertaken at the University of Khartoum. Using accredited citation typologies, the current study has attempted to gauge the quality of these citations within the Literature Review Chapter of 10 Sudanese theses, which are pitted against an equal number of British theses produced at The University of Glasgow. The latter corpus has the undoubted advantages of the intuition of the native speakers as well as a superior pedagogical and academic milieu. Areas of comparison related to such aspects as citation density, the ratio of integral to non-integral citations, the distribution of the various subsets of integral and non-integral citations and, finally, the relative frequency of reporting verbs and the categorization of denotative and evaluative functions in the two corpora. The statistical part was followed by an in-depth discussion that related the above citation roles, as embodied in the relation between the citing writer and the cited author. Notions of attribution, averral, textual voice and knowledge transformation were discussed and instantiated within the various functions of the Literature Review.

Regarding the findings, both corpora contained high densities of overall citation features, which fact could be attributed to the discursive and interdisciplinary nature of Applied Linguistics that draws on such realms as Sociology, Philosophy, Cultural Studies, Pedagogy and Computational Sciences, as particularly evident in the diversity of subject matter in the British corpus. Also, the two corpora exhibited a similar tendency to foreground author overwhelming use of integral citations, which, again, is consistent with canonical studies (e.g. Hyland, 2002; Thompson, 2005) on the primacy of human agency in the construction of knowledge in social fields. Features such as the distribution of adjunct structures, thematization or passivization were not appreciably different in the two corpora. However, it seems that similarities end here, and that great discrepancies exist in the way the two groups handle citations both formally and functionally. The British writers were largely exempt from many of the citation errors committed by their Sudanese peers. Indeed, as shown through innumerable examples, the Sudanese scholars lack the basic knowledge of howto document their sources. There are blatant and systematic examples of total as well as virtual miscitations, inappropriate use of personal evaluative epithets, verbose unanalyzed naïve quotations, and of verbal redundancy and repetitions irrespective of the rhetorical purpose and, which frequently degenerates into non- idiomatic or semantically inappropriate verb choice. Yet, it is the functions of citations that vastly differentiate the two corpora. Of the roles of a good Literature Review that include synthesis of sources, determination of one's research in relation to the state-of-the-art references, critical analysis of the literature with a view to initiating new vistas and methodologies, and utilization of the literature as a subservient tool to consolidate the insights offered by the new research, it can be plausibly claimed that the Sudanese scholars merely fulfill the first requirement. As illustrated by many representative excerpts, the Sudanese Literature Review is virtually Author-oriented; it is practically a collation of previous studies and constructs that lack coherence in relation to the writer's perspectives. The dominance of Non-integral Source citations is mirrored in the virtually complete deployment of Author-based reporting verbs. These two categories constitute almost all of the occurrences of citations in the corpus, and both meet the rudimentary function of attribution of citations to their original authors, and, hence, demonstration of a re knowledge of the literature. On the other hand, the British made a much more skillful use of other categories of Non-integral citations to control their writing, indicating their mastery through referring readers both to intra-textual as well as well as extra-textual materials and exemplifying relevant texts. More substantially, while the British scholars, too, relied predominantly on Author- oriented prose typical of a Literature Review, they employed a small, but significant, proportion of Writer Acts either to positively or critically appraise the literature at appropriate points, thereby ensuring that it is the tenor of their argument that is dominant and that even the most heavy consultation of citation is directed at the elucidation of their positions, generation of new 
insights and approaches that are pertinent to the current research and its writer, who would frequently resort to the first person pronoun to illustrate that, ultimately, all citations are instrumental for establishing a more potent authorial self. In contrast, Sudanese scholars almost wholly employ neutral Author Acts which can be equated with Non-integral Source since they, too, attribute a theory or an investigation to a textual agent. The researcher's textual voice is mute, and neither the views nor studies presented are analyzed, interwoven or contrasted within the overarching knowledge-transforming theme of the thesis. It can, therefore, be concluded that such perfunctory, reproductive and synthetic research as that submitted by the Sudanese scholars hardly satisfies the characteristics of a proper Literature Review, and may be claimed to cast grave doubts upon the soundness of methods employed and the quality of the thesis as a whole.

Taking into consideration the enormous difficulties experienced by the Sudanese scholars in appropriately citing sources, pedagogical measures need to be implemented to ameliorate this situation. But, it is important to recognize that the Sudanese candidates probably have many hurdles in handling conventions of academic writing (of which citation is but one). Indeed, to remedy the problems above, it is useful to conceptualize the research environment and such factors as the fragmented discourse community, the insidious rivalry between Arabic and English as the research medium of instruction and the political and academic insularity of the country (Ali, 2016). More specific detrimental factors relate the facile outdated view (embodied in the common-core ESP textbooks taught at the undergraduate level) of a monolithic self-evident academic register cutting across all disciplines, resulting in the absence of any post-graduate programmes on discipline-specific academic literacy (Ali, 2011, 2016). Hence, there is a dire need to recognize the challenges posed by research such as the Ph.D. thesis crucial to initiation into the discourse community. The fractious relation between candidates and supervisors has already been noted by Alhassan and Holi (2016). It is fair to believe that that supervisors are a key element of the success of the Ph.D. thesis in terms of the expertise and intellectual stimulus and counseling activities to ensure the production of an acceptable thesis (Zeegers and Barron, 2012). Their advice and insights regarding the linguistic aspects of the thesis are crucial to the success of such unprivileged, under-resourced and linguistically deficient candidates, as those in Sudan.

Genre analysis is a powerful heuristic for sensitizing students to how linguistic and rhetorical choices in research genres (including the Ph.D.) are conditioned by the different disciplinary concerns of their respective discourse communities, and such conventional modes of argumentation are cast in different academic garbs for each discipline. A twin idea of disciplinary conglomerations ranging from pure objective sciences to more contingent and interpretive social fields and ending in wholly discursive and fluid Humanities (Hyland, 2006) is beneficial, as helps locate the citation conventions of Applied Linguistics in terms of manner of textual integration and voice, paraphrases, human agency and presentation of arguments. A genre analysis would ideally not merely focus on exemplary (particularly native) samples of Applied Linguistics theses, but also contrast them with citation norms in other academic tribes (Becher and Trowler, 2001) and relate them to the conceptual and epistemological Weltanschauung of the discipline, as seen in the varying degrees of citation densities, integration, quotation, and discursive, cognitive and research activities and patterns of attribution of cited materials. In fact, researchers (e.g. Thompson, 2005; Swales and Feak, 2012; Morako, 2013) have proposed a full-fledged genre pedagogy that can be applied by supervisors and syllabus designers in Sudan. The salient features of this approach include in-depth analysis by candidates of selected research projects they have produced, and these can be used by the supervisor as points of comparisons against the preferred citation practices in Applied Linguistics, and how these rhetorical forms inhere in the communicative purposes of research in this field. Analysis of functions can be accompanied by explicit exercises, where candidates are trained to express the different degrees of propositional responsibility and textual evaluation. Candidates can improve their understanding through peer-reviews, metacognitive reflection and discussions with supervisors and colleagues. Finally, supervisors can utilize the limitless potentials of corpus linguistics, which has developed such programmes as The Wordsmith Tools (2014) for quantification of linguistic aspects of colossal corpora. Using such tools, analysis can be made of an infinite number of Ph.D. theses, and citation patterns can be concordanced to allow for the enumeration of all instances of citations at the centres of potentially thousands of pages. Hence, the user can scan both the citation forms and the surrounding textual environment, including the reporting verbs. Corpus strategies are of particular significance when supervisors wish to compare candidates' writing against international models (e.g. The University of Glasgow, in our case). Alternatively, learner corpora can be compiled and used to teach candidates about the intricate nature of reporting or the relation between averral and attribution both in Applied Linguistics and the whole spectrum of knowledge domains.

This has only been a tentative contrastive study of citation practices in the Literature Review between a native and a non-native sample of Ph.D. candidates. It can be complemented through comparisons of other theses, from other 
parts of the knowledge continuum (e.g. Chemistry, Medicine, Agriculture or Economics) to verify whether the Sudanese candidates in these fields replicate the above inconsistencies and divergences from British and standard disciplinary practices. Equally, parallel contrastive studies of citations can be undertaken between local Research Articles produced in Sudan and those pertaining to internationally recognized journals. Also, the present study can be strengthened through discourse-based and semi-structured interviews with candidates and supervisors regarding their conceptions of the roles and manifestations of intertextuality within their disciplines, and the views of active candidates can be juxtaposed against samples of thesis-in-process to explore their introspections on their preferences of certain forms rather than others. These investigations can be extended to studying the politics of citations in terms of such factors as clusters of authorship, types of documents consulted, and place and date of publication. A critical discourse analysis can be conducted to relate these patterns to institutional, disciplinary, generational and geopolitical settings. Finally, studies can trace the efficacy of explicit citation teaching within the framework of genre analysis theory on the actual practices of $\mathrm{Ph}$. D. candidates in the various disciplines, and assessment can take the form of comparing the pre-treatment and post-treatment research versions.

\section{References}

Abdallah, A. Y. (2000). Investigating Sudanese EFL learners' written discourse competence: Unpublished Ph.D. Thesis, University of Khartoum: Sudan

Alhassan, A. A., \& Holi, A. I. (2016). An Evaluation of Sudanese Linguistics and English Ph.D. Candidates' Challenges and Problems: An Exploratory Study. In S. Hidri and C. Christine (Eds.), Evaluation in Foreign Language Education in The Middle East and North Africa. Geneva: Springer.

Ali, N.A. (2011). Manifest Intertextuality in Academic Discourse: An Interdisciplinary Study of Geology, Geography and Applied Linguistics Ph.D. Theses. Unpublished Ph.D. Thesis. University of Khartoum, Sudan.

Ali, N.A. (2016). Metadiscourse in Academic Genres: An Interdisciplinary Study of Research Articles in Sudan. British Journal of Applied Linguistics, 4(5), 35-63.

Bakhtin, M. (1981). The Dialogic Imagination. In C. Emerson, \& M. Holquist (Eds.), Austin, Texas: University of Texas Press.

Bakhtin, M. (1986). The Problems of Speech Genres and Other Late Essays. In. C. Emerson, \& M. Holquist (Eds.), Austin: University of Texas Press.

Bereiter, C., \& Scardamalia, M. (1987). The psychology of written composition. Hillsdale, NJ: Lawrence Erlbaum Associates.

Berkenkotter. C., \& Huckin. T. (1995). Genre Knowledge in disciplinary communication. Hillsdale, Nj: Lawrence Erlbaum.

Bloch, J. (2010). A concordance-based study of the use of reporting verbs as rhetorical devices in academic papers. Journal of Writing Research, 2(2), 219-244.https://doi.org/10.17239/jowr-2010.02.02.7

Boote, D. N., \& Beile, P. (2005). Scholars before researchers: On the centrality of the dissertation literature review in research preparation. Educational Researcher, 34(6), 3-15.

Bruffee. K. (1986). Social construction: language and the authority of knowledge: a bibliographical essay. College English, 48, 773-9. https://doi.org/10.2307/376723

Brydon, K., \& Fleming, J. (2011). The journey around my PhD: Pitfalls, insights and diamonds. Social Work Education: The International Journal, 30(8), 995-1011. https://doi.org/10.1080/02615479.2010.527936

Bunton, D. (2002). Generic moves in Ph D thesis introductions. In J. Flowerdew (Ed.), Academic discourse. Harlow: Pearson.

Charles, M. (2006). Phraseological patterns in reporting clauses used in citation: a corpus-based study of theses in two disciplines. English for Specific Purposes, 25, 310-331. https://doi.org/10.1016/j.esp.2005.05.003

El Malik. A., \& Nesi, H. (2008). Publishing research in a second language: The case of Sudanese contributors to international medical journals. Journal of English for Academic Purposes 7, 87-96. https://doi.org/10.1016/j.jeap.2008.02.007

Fairclough, N. (1992). Discourse and Text: Linguistics and Internal Analysis within Discourse Analysis. Discourse and Society, 3(2), 193-227. https://doi.org/10.1177/0957926592003002004 
Geertz, C. (1983). Thick description: Towards an interpretive theory of culture. New York: Basic Books. .

Gilbert, G. N. (1977). Referencing and persuasion. Social Studies of Science, 7, $113-122$. https://doi.org/10.1177/030631277700700112

Groom, N. (2000). A workable balance: Self and sources in argumentative writing. In S. Mitchell, \& R. Andrews (Eds.), Learning to argue in higher education (pp. 65-73). Portsmouth: Boynton/Cook.

Hart, C. (1998). Doing a Literature Review. Sage: London.

Hawes, T., \& Thomas, S. (1994). Reporting verbs in medical journal articles. English for Specific Purposes, 13(2), 129-148. https://doi.org/10.1016/0889-4906(94)90012-4

Howard, N. (2008). An Interview Based Study of the Functions of Citations across two disciplines. Journal of Pragmatics (a pr-print).

Hyland, K. (2001). Humble servants of the discipline? Self-mention in research articles. English for Specific Purposes, 20(3), 207-226. https://doi.org/10.1016/S0889-4906(00)00012-0

Hyland, K. (1996). Writing without conviction? Hedging in scientific research articles. Applied Linguistics, 17, 433-454. https://doi.org/10.1093/applin/17.4.433

Hyland, K. (2000). Disciplinary discourse: Social interactions academic writing. Harlow: Longman

Hyland, K. (2002). Activity and evaluation: Reporting practices in academic writing. In J. Flowerdew (Ed.), Academic discourse. Harlow: Longman

Hyland, K. (2004). Disciplinary interactions: metadiscourse in L2 postgraduate writing. Journal of Second Language Writing, 13, 133-151. https://doi.org/10.1016/j.jslw.2004.02.001

Hyland, K. (2005). Metadiscourse. London: Continuum;

Hyland, K. (2006). Englishfor Academic Purposes: An Advanced Resource Book. London: Rutledge.

Koerner, E. F. K. (1999). The concept of 'revolution' in linguistics: Historical, methodological, and philosophical considerations. History of Linguistics 1996: Selected Papers from the Seventh International Conference on the History of Linguistics. Oxford, England, 12-17 September .Ed. by David Cram. https://doi.org/10.1075/sihols.94.05koe

Kwan, B. S. C. (2006). The schematic structure of literature reviews in doctoral theses of applied linguistics. English for Specific Purposes, 25(1), 30 - 55. https://doi.org/10.1016/j.esp.2005.06.001

Loan, T, N., \& Pramoolsook, I. (2015). Reporting Verbs in Literature Review of Vietnamese TESOL Master Thesis. ESP TODAY, 3(2), 196-215.

Mansourizadeh, K., \& Ahmad, U. K. (2011). Citation practices among non-native expert and novice scientific writers. Journal of English for Academic Purposes, 10(3), 152-161. https://doi.org/10.1016/j.jeap.2011.03.004

Maroko, G, M. (2003). Citation Practices in Selected Science and Humanities Dissertations: Implications for Teaching. American Journal of Educational Research, 1(4), 126-136.

Paltridge, B. (2002). Thesis and dissertation writing: An examination of published advice and actual practice. English for Specific Purposes, 21, 125-143. https://doi.org/10.1016/S0889-4906(00)00025-9

Pecorari, D. (2006). Visible and occluded citation features in postgraduate second-language writing. English for Specific Purposes, 25(1), 4-29. https://doi.org/10.1016/j.esp.2005.04.004

Pennycook, A. (1996). Borrowing others' words: Text, ownership, memory and plagiarism. TESOL Quarterly, 30(2), 201-230. https://doi.org/10.2307/3588141

Petrić, B. (2007). Rhetorical functions of citations in high- and low-rated master's theses. Journal of English for Academic Purposes, 6(3), 238-253. https://doi.org/10.1016/j.jeap.2007.09.002

Pyhältö, K., Toom, A., Stubb, J., \& Lonka, K. (2012). Challenges of becoming a scholar: A study of doctoral students' problems and well-being. International Scholarly Research Network, 2012, 1-12. https://doi.org/10.5402/2012/934941

Ridley, D. (2000). The different guises of a Ph D thesis and the role of a literature review. In P. Thompson (Ed.), Patterns and perspectives: Insights into EAP writing practice. Reading, UK: University of Reading Press. 
Rose, S. K. (1996). What's love got to do with it? Scholarly citation practices as courtship rituals. Research on the Language of the Discipline, 1(3), 34-48.

Samraj, B. (2008). A discousal analysis of Master theses across disciplines with focus on introductions. Journal of English for Academic Purposes, 7, 55-67. https://doi.org/10.1016/j.jeap.2008.02.005

Samraj, B. (2013). Form and function of citations in discussion sections of master's theses and research articles. Journal of English for Academic Purposes, 12(4), 299-310. https://doi.org/10.1016/j.jeap.2013.09.001

Shaw, P. (1992). Reasons for the correlation of voice, tense, and sentence function in reporting verbs. Applied Linguistics, 13(3), 302-319. https://doi.org/10.1093/applin/13.3.302

Soler-Monreal, C., \& Gil-Salom, L. (2012). A cross-language study on citation practice in Ph.D. theses. International Journal of English Studies, 11(2), 53-75.

Swales, J. (1990). Genre analysis: English in academic and research settings. Cambridge: Cambridge University Press.

Swales. J., \& Feak. C. (2012). Academic writingfor graduate students: Essential tasks and skills (3rd ed.). Ann Arbor: University of Michigan Press.https://doi.org/10.3998/mpub.2173936

Swales, J. (2004). Research Genres. Cambridge: Cambridge University Press. https://doi.org/10.1017/CBO9781139524827

Thompson, G., \& Ye, Y. (1991). Evaluation in the reporting verbs used in academic papers. Applied Linguistics, 12(4), 365-382.

Thompson, P. (2001). A pedagogically-motivated corpus-based examination of Ph.D. theses: Macrostructure, citation practices and uses of modal verbs. (Unpublished doctoral dissertation). University of Reading, UK.

Thompson, P. (2005). Points of focus and position: intertextual reference in Ph. D theses. Journal of English for Academic Purposes, 4, 307-323. https://doi.org/10.1016/j.jeap.2005.07.006

Thompson, P. (2009). Literature reviews in applied PhD theses: Evidence and problems. In K.Hyland. \& G. Diani (Eds.), Academic Evaluation. Review Genres in University Settings (pp. 50-67). London: Palgrave Macmillan.

Thompson, P. (2002). Manifest Intertextuality in the Ph.D. Thesis. REVISTA CANARIA DE ESTUDIOS INGLESES, 44, 97-114.

Weissberg, R., \& Buker, S. (1990). Writing up research: Experimental research report writing for students of English. Englewoods Cliff, NJ: Prentice.

White, H. D. (2004). Citation analysis and discourse analysis revisited. Applied Linguistics, 25, 89-116. https://doi.org/10.1093/applin/25.1.89

Widdowson, H. G. (1993). The relative conditions of Language use and Learning. In M. Krueger \& F. Rayan (Eds.). Language and Context. Descriptive and Content Based Approaches to Language Studying. Lexington: MA. D. C. Heath.

\section{Details of Theses Used in the Corpus}

SA1: S. Y. Ismail. (2003). Language Acquisition Strategies Among Sudanese School Children.

SA2: M. Y. Mohammed. (2008). Collocational Knowledge Among EFL Students: The Case of Sudanese English Majors.

SA3:M. A. Al Amin. (2007). Maintaining Interaction in Sudanese Large Classes Through the Communicative Approach.

SA4: M. Ahmad. (2009). The Effects of Grammatical, Lexical and Cultural Background Knowledge on Reading Comprehension.

SA5: M. D. Salih. (2010). The Relationship between Teachers' Professional Competence and Young Learners' LanguageDevelopment.

SA6; S. N. Mohammed. (19980. Influence of Certain Factors on Choice of Interlanguage Communication Strategies.

SA7: A. H. Abdalla. (2009). The Role of Consciousness-raising in Explicit Grammar Teaching 
SA8: F. A. Mohammed. (2011). Transfer Errors in Sudanese EFL Students.

SA9: F. O. Al Haj. (2006). The Role of Idioms in Foreign Language Teaching in Sudan.

SA10: O. B. Gasm Allah. (2004). The Relationship between Vocabulary Knowledge and Reading Comprehension.

BA1: D.R. Hill. (2015). A genre Analysis of Medical Research Articles.

BA2: H. R. Louise. (2016). Colour in English from Metonymy to Metaphor.

BA3: A.D. Elizabeth. (2002). Exploring Students' and Teachers' Perceptions of Role in Hong Kong English Classrooms.

BA4: G.A. Elizabeth. (2003). Scandinavian Place-names in Northern England as Evidence of Language Contact.

BA5: O. McCarthy. (2011). AA Study of Realization of Velar Plosives Among Female Pupils in Glasgow.

BA6: A. Myer. (2000). Language As A Social Tool of Control and Resistance: Discourse Analysis in A prison Setting.

BA7: D. Robertson. (2015). Implicit Cognition and the Social Evaluation of Speech.

BA8: J.A. Shaver. (2010). Metaphors of Travel in the Language of Hymns 1650-1800.

BA9: W.C. Michael. (2010). Attitudes Towards English Phrasal Verbs in the Late Modern Period.

BA10: M.C. Jones. (2000) .Vernacular Literacy in Late Medieval England: The Example of East Anglian Medical Manuscripts. 